\title{
Anesthetic Considerations for Adults Undergoing Fontan Conversion Surgery
}

\author{
Emad B. Mossad, MD a,b,*, Pablo Motta, MD ${ }^{a, b}$, \\ David F. Vener, $M D^{a, b}$
}

\section{KEYWORDS}

- Adult congenital heart disease $\bullet$ Fontan operation $\bullet$ Venous capacitance

- Protein-losing enteropathy

\section{KEY POINTS}

- Adults with congenital heart disease are a growing population with residual defects that require repeat interventions. The care of these patients will increasingly require a care team with an understanding of the unique physiology and anatomy of these patients.

- The Fontan conversion operation is an evolution in surgical intervention for patients with single ventricles and failed prior operations.

- Patients with single ventricular repair have significant comorbidities and unique physiologic status that must be considered by the anesthesiologist.

\section{INTRODUCTION}

Patients more than 18 years of age now represent the largest group of patients with congenital heart defects (CHDs), with a population growing at a rate of $5 \%$ to $7 \%$ annually. ${ }^{1,2}$ The most common operations in the Society of Thoracic Surgery (STS) Congenital Heart Surgery Database for patients more than 18 years old for the years 2008 to 2011 are outlined in Table 1. During this period, 6234 procedures were performed on 5892 patients. ${ }^{3}$ Although these numbers remain small compared with the overall number of adult cardiac operations, they represent one of the only adult cardiac surgical populations that is continuing to grow.

The first groups of children with surgically repaired cyanotic defects, primarily those with tetralogy of Fallot, as well as those with more straightforward defects

Disclosures: The authors have all contributed equally to the article. None of the authors have any conflict of interest related to this work.

a Baylor College of Medicine, Houston, TX, USA; ${ }^{b}$ Division of Pediatric cardiovascular Anesthesia, Texas Children's Hospital, 6621 Fannin Street, Suite W17417, Houston, TX 77030, USA

* Corresponding author. Texas Children's Hospital, 6621 Fannin Street, Suite W17417, Houston, TX 77030.

E-mail address: ebmossad@texaschildrens.org 


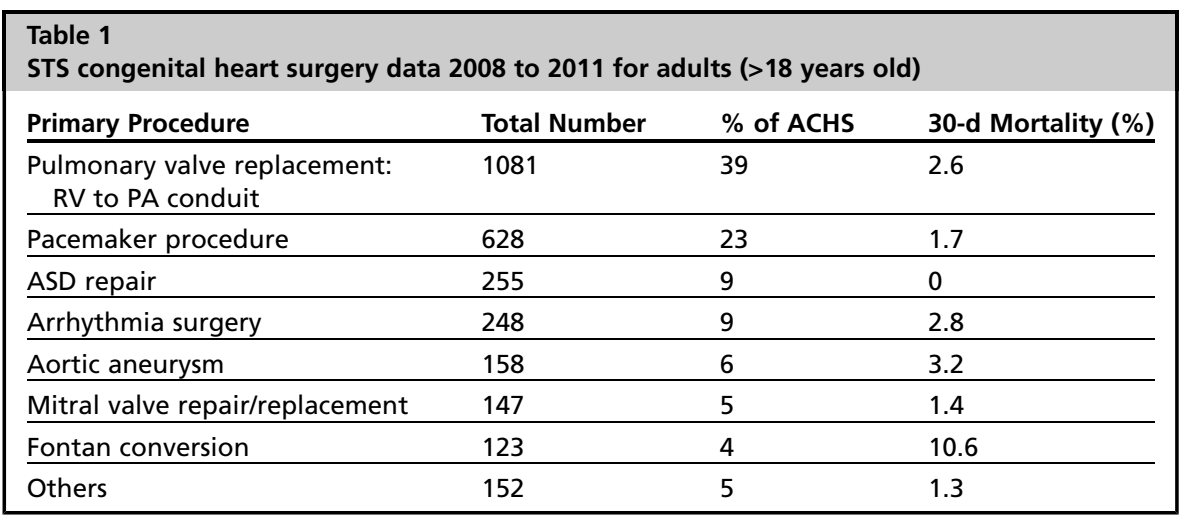

Abbreviations: ACHS, adult congenital heart surgery cases; PA, pulmonary artery.

Data from Society of Thoracic Surgeons Congenital Heart Surgery Executive Summary, Duke Clinical Research Institute. Available at: http://www.sts.org/sites/default/files/documents/STSExecSummary Adults.pdf. Accessed December 19, 2012.

such as atrial septal defects, are now more than 50 years of age. In addition, a growing cohort of patients with more complex lesions is now surviving into their 20 s and 30 s, and potentially beyond, although their lifespan remains significantly shorter than those without CHD. ${ }^{3}$ With the progress of care and long-term followup, it is now evident that many of the patients who had complete repairs as infants and children require ongoing monitoring throughout their lifetime and may require subsequent surgeries to repair progressive disease processes such as conduit failure or dilatation, valve insufficiency, aneurysm development, or residual defects. In addition, many of these patients, particularly those with right ventricular outflow lesions and those with single-ventricle physiology, require repeat operations or planned surgical modifications, including conduit revisions, Fontan conversion surgery, or heart transplantation because of progressive heart failure. A large cohort of these patients require multiple interventions in both the operating room and cardiac catheterization laboratories for electrophysiology investigations and ablations for arrhythmia management, percutaneous valve insertion, placement and dilations of stents, and other procedures. ${ }^{4}$ Because of the complexity of their diseases and the need for reoperations, the risk profile for these patients significantly exceeds that of patients without CHDs. ${ }^{5}$

Adult patients with CHDs are often still followed and treated by pediatric specialists, including cardiologists, surgeons, and anesthesiologists in children's hospitals. These patients comprise $5 \%$ to $10 \%$ of the annual surgical volume in many children's hospitals and a significant number of catheter interventions in these hospitals (Fig. 1). These patients are increasingly seen by adult providers, including adult cardiac anesthesiologists. There are now a few programs around the country that have begun to specialize in the treatment of this unique population. ${ }^{5,6}$ Caring for this population requires familiarity with congenital cardiac defects, their surgical and medical treatment, and the underlying physiology in order to safely manage their perioperative course. Giamberti and colleagues ${ }^{5}$ showed that the training and experience of the surgical and anesthesia care team may affect patient outcomes. Most of the procedures that require repeat sternotomy, such as conduit revisions or aortic aneurysm repairs, have perioperative mortalities no higher than $3.2 \%$, but each subsequent reoperation carries increasing morbidity (Fig. 2). ${ }^{5}$ 


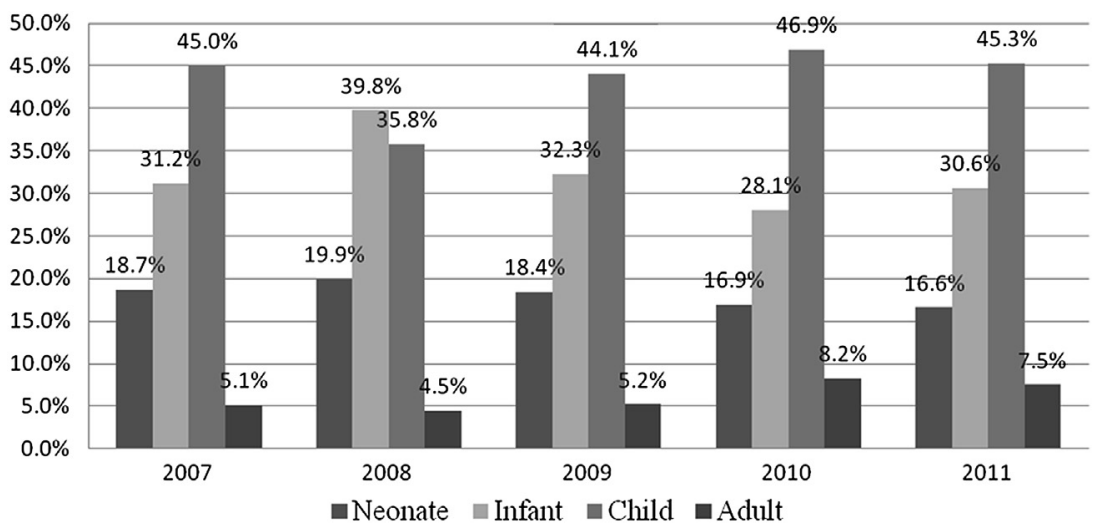

Fig. 1. Texas Children's Hospital Heart Center cardiovascular and thoracic surgery case volume by age (2007-2011). (Data from Texas Children's Hospital. Heart Center Outcomes Book 2011. Available at: http://www.texaschildrens.org/uploadedFiles/2011-Heart-CenterOutcomes.pdf. Accessed March 12, 2013.)

\section{EVOLUTION AND OUTCOMES OF THE FONTAN CONVERSION SURGERY History}

The first successful single-ventricle surgeries were described independently in the early 1970s by Fontan and Baudet ${ }^{7}$ in France and Kreutzer and colleagues $^{8}$ in Argentina for the treatment of tricuspid atresia. These single-ventricle repairs involved creating a direct anastomosis between the right atrium (RA) and pulmonary artery, bypassing the right ventricle (RV) and creating a passive pulmonary blood flow pattern, typically using the right atrial appendage as a conduit to the pulmonary artery (Fig. 3A). Variations on this surgery have become the treatment of choice for single-ventricle anatomy of all types, including hypoplastic left heart syndrome and its variants as well as complex atrioventricular canal defects and others. With advances in surgical

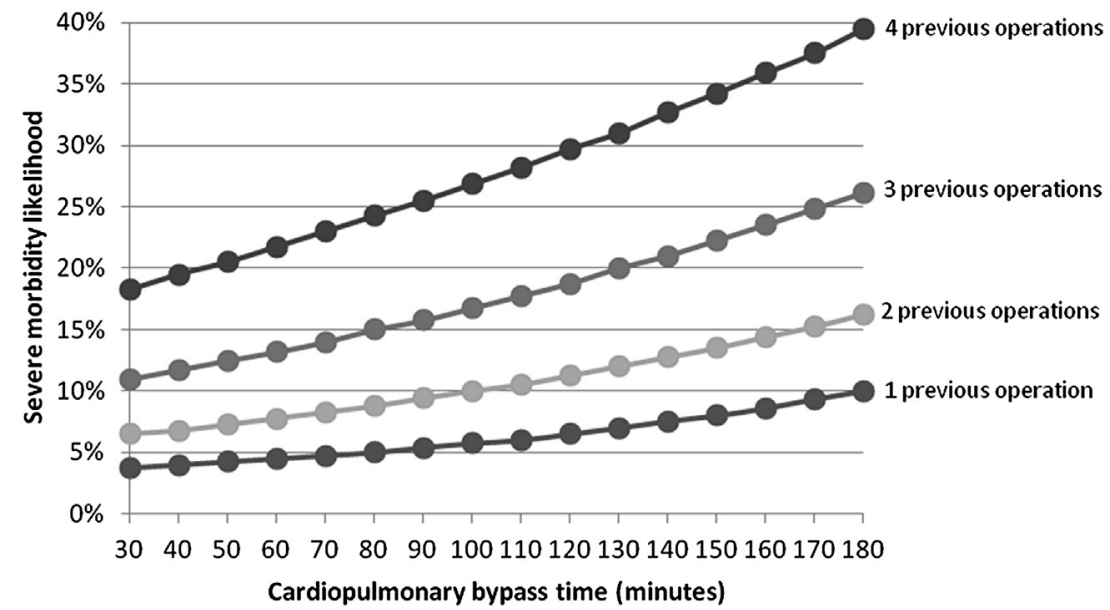

Fig. 2. Morbidity likelihood in adult congenital heart surgery as it relates to cardiopulmonary bypass duration and number of previous cardiac operations. (Data from Giamberti A, Chessa $\mathrm{M}$, Abella R, et al. Morbidity and mortality risk factors in adults with Congenital Heart Disease Undergoing Cardiac Reoperations. Ann Thorac Surg 2009;88:1284-90; with permission.) 

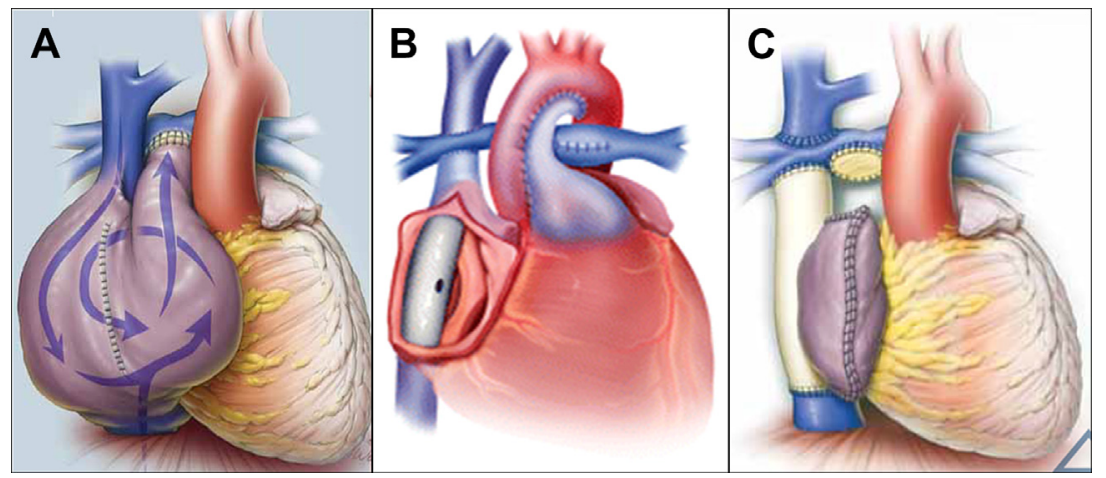

Fig. 3. (A) Atriopulmonary (classic) Fontan repair. (B) Lateral tunnel (fenestrated) Fontan repair. (C) Extracardiac Fontan repair. $([A, C]$ From Texas Children's Hospital. Heart Center Outcomes Book 2011. Available at: http://www.texaschildrens.org/uploadedFiles/2011Heart-Center-Outcomes.pdf. Accessed March 12, 2013; and [B] From Gaca AM, Jaggers JJ, Dudley LT, et al. Repair of congenital heart disease: a primer - part 1. Radiology 2008;247: 617-31; with permission.)

techniques and experience, modifications in surgical strategy were developed to account for variations in anatomy as well as to minimize complications associated with the original surgery that became more obvious as patients survived into adulthood.

The most frequent complications following the atriopulmonary Fontan include massive right atrial dilatation, atrial arrhythmia development, protein-losing enteropathy (PLE) and progressive heart failure, particularly in patients with a functional RV acting as the systemic chamber. Late surgical complications such as progressive anastomotic stenosis may also contribute to the need for reoperations. Nonetheless, many of the surviving patients have a reasonable quality of life. ${ }^{9}$

Subsequent surgical improvements after the initial reports by Fontan and Baudet ${ }^{7}$ and Kreutzer and colleagues ${ }^{8}$ included staging the procedure by the creation of a Glenn shunt (bidirectional connection from the superior vena cava to the pulmonary artery) followed by completion of the Fontan with an intracardiac lateral tunnel (LT) or hemi-Fontan and now more commonly the extracardiac (EC) Fontan (see Fig. 3B, C). ${ }^{10}$ In addition, some circumstances such as a high pulmonary artery resistance may indicate the need for a fenestration within the repair to allow a pop-off of the systemic venous pathway and preservation of cardiac output. During the period of 2008 to 2011 in the STS Database, Fontan completion, in its most common variants, accounted for $3.8 \%$ of all operations performed and $10.4 \%$ in children between the ages of 1 and 18 years. $^{3}$

\section{Indications and Benefits of Fontan Conversion}

Following the initial success of the original Fontan repairs, long-term follow-up showed premature decline in survival and functional status of these patients. ${ }^{11}$ Despite a perfect Fontan operation, patients followed for a median of 12.2 years had an actuarial freedom from death or transplantation of less than $80 \%$ at 20 years, with many patients suffering debilitating arrhythmias (10\%), thromboembolic events (7.9\%), and heart failure-related symptoms $(7 \%){ }^{12}$ These consequences identify the palliative rather than curative nature of the Fontan state, primarily because progressive atrial dilatation results in fluid energy loss, effective pressure decrease, and fluid resistance along the pathway. ${ }^{13}$ This condition is manifested by worsening 
exercise capacity, lower anaerobic thresholds, and increased endothelin-1 and brain and atrial natriuretic peptides. ${ }^{14}$

Fontan conversion surgery refers to procedures in which the original systemic venous-to-pulmonary-artery anastomosis is taken down and a modified pathway is constructed to decompress the RA in an attempt to enhance forward flow through the passive Fontan pathway, decrease the risk of arrhythmias and thromboembolic events, and improve survival. These procedures are most commonly performed in the late teenage years and beyond, when the complications of the original surgery become intolerable. Fontan conversion surgery is particularly high risk because of multiple factors, including repeat sternotomy, advanced heart failure, and significant arrhythmias. It is commonly accompanied by arrhythmia surgery with intraoperative cryoablation of the atrial endocardium in a maze operation and may also involve valvuloplasty of insufficient atrioventricular valves. Of the most frequent procedures in the latest STS Congenital Heart Surgery Database report (2008-2011), Fontan revision or conversion is the 10th most common performed on adult patients, but it carries the highest mortality (123 procedures reported with a 10.6\% 30-day mortality) (see Table 1).

\section{LT Versus EC Repairs}

Indications for Fontan conversion in an adult who has previously undergone a classic atriopulmonary Fontan include a combination of increasing symptoms of systemic ventricular failure, refractory arrhythmias, and other complications related to obstructed or sluggish flow in the Fontan pathway. Surgical options for the Fontan conversion include LT and EC repairs with/without arrhythmia surgery and pacemaker placement. Although there are theoretic advantages to each of the two approaches (Table 2), most reports show a similar short and intermediate follow-up conduct, including similar in-hospital mortality, hospital length of stay, improvement in New York Heart Association (NYHA) class, recurrence of arrhythmias, and late death. ${ }^{15,16}$

\section{Texas Children's Hospital Fontan Conversion Data}

The experience of several institutions with the Fontan conversion surgery for adults suffering from a variety of sequelae of the original repair is encouraging. Survivors

\begin{tabular}{|lll|}
\hline $\begin{array}{l}\text { Table } 2 \\
\text { Comparison of LT and EC Fontan } \\
\text { LT Fontan }\end{array}$ & EC Fontan \\
\hline Potential advantages & $\begin{array}{c}\text { Positive growth potential, } \\
\text { especially in young patients } \\
\text { Ease of fenestration when } \\
\text { indicated } \\
\text { Avoidance of conduit-related } \\
\text { issues (stenosis, thrombosis) }\end{array}$ & $\begin{array}{c}\text { Flexibility in anatomically variable } \\
\text { morphology (heterotaxy) } \\
\text { Avoidance of sinus node } \\
\text { manipulation }\end{array}$ \\
& $\begin{array}{c}\text { Fewer atrial incisions and suture } \\
\text { lines (low risk for arrhythmias) }\end{array}$ \\
& $\begin{array}{c}\text { Potential for a shorter } \\
\text { cardiopulmonary bypass and } \\
\text { avoidance of aortic cross-clamp } \\
\text { and cardioplegic arrest }\end{array}$ \\
\hline Potential disadvantages & $\begin{array}{c}\text { Higher incidence of sinus node } \\
\text { dysfunction, IART, and SVT } \\
\text { Need for cross-clamp and } \\
\text { cardioplegic arrest to } \\
\text { complete the repair }\end{array}$ & $\begin{array}{c}\text { Rigid, fixed-size conduit with } \\
\text { potential for obstruction and/or } \\
\text { stenosis } \\
\text { Higher risk of thromboembolism }\end{array}$ \\
\hline
\end{tabular}

Abbreviations: IART, intra-atrial reentrant tachycardia; SVT, supraventricular tachycardia. 
of the conversion experience an improvement in functional status, decreased debilitating arrhythmias, and reduced need for medical therapy. ${ }^{17,18}$ Our experience at Texas Children's Hospital over the past 15 years with 61 Fontan conversions is summarized in Box 1. Timing of referral of these patients is critical for a favorable outcome, and should be considered with the early onset of arrhythmia and other markers of a failing Fontan pathway. The success of this complicated procedure requires the involvement of the cardiac anesthesiologist in the preoperative risk assessment and understanding of the impact of the interventions on Fontan physiology.

\section{PERIOPERATIVE CONSIDERATIONS FOR THE ADULT UNDERGOING FONTAN CONVERSION \\ Risk Stratification}

Adults presenting for Fontan conversion are at significant risk for early intraoperative and postoperative complications. The preoperative anesthetic evaluation should focus on the variables that contribute to increased morbidity. These variables include the presence of preoperative arrhythmias, functional class and single-ventricular morphology, desaturation caused by a fenestration, baffle leak or decompressing collaterals, presence of PLE, and history of stroke or other thromboembolic events. A proposed risk score identifies these variables as the FACET score (Box 2). ${ }^{19}$

\section{Transesophageal Echocardiography Before and After Repair}

Two-dimensional transesophageal echocardiography (TEE) helps to define the type of single-ventricle morphology based on the atrioventricular (AV) connection, the ventriculoarterial connection, and the ventricular morphology. The type of AV connection

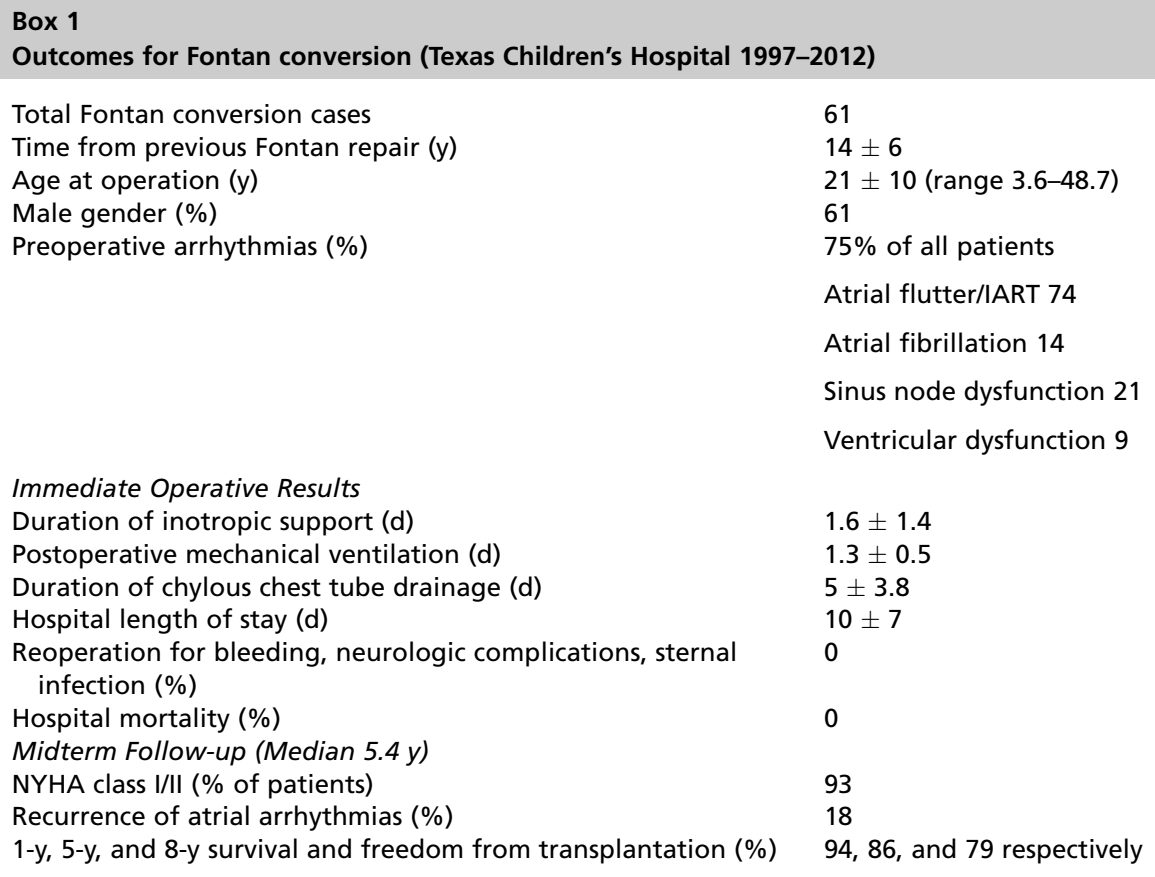

$1.6 \pm 1.4$
$1.3 \pm 0.5$
$5 \pm 3.8$
$10 \pm 7$
0
0
93
18
94,86, and 79 respectively




\begin{tabular}{|ll|}
\hline Box 2 & \\
FACET risk stratification for Fontan conversion \\
F & Functional class (NYHA) \\
& Systolic function: normal (1), mild (2), moderate (3), severe (4) \\
A & Arrhythmia \\
C & Desaturation $\left(\mathrm{Spo}_{2}<90 \%\right)$ \\
E & PLE: \\
& Recurrent chylous effusions \\
T & Hypoalbuminemia (<3 $\mathrm{g} / \mathrm{dL}$ for $>3$ months) \\
\hline
\end{tabular}

can help to diagnose double-inlet ventricle ( $>50 \%$ of both AV valves [AVV] open into a single ventricle), unbalanced AV canal defect ( $>75 \%$ of a common AV valve opening into 1 ventricle), and the AV valve atresia if there is lack of connection between atrium and ventricle (tricuspid atresia or mitral atresia). The ventriculoarterial connection differentiates between double-outlet RV, transposition of the great arteries, and great vessel atresia when there is only 1 ventricular outlet (right-side lesion, pulmonary atresia; left-side lesion, aortic atresia). The ventricular morphology based on its relationship with AV valves (tricuspid is committed to RV, mitral to left ventricle [LV]), moderator band and trabeculations (RV hallmarks) help to differentiate the morphologic RV from LV in transposition cases. ${ }^{20}$

Doppler interrogation is important to assess the Fontan connections (inferior vena cava to RA/conduit, superior vena cava to RA/conduit), AV and semilunar valves for obstruction/regurgitation, confirm unrestrictive atrial level shunting (Fig. 4A, B) and unobstructed pulmonary venous flow, and estimation of gradient across any outflow tract obstruction. All these abnormal flow patterns should be addressed during the Fontan palliation and/or Fontan conversion and require aortic cross-clamping. Other complications of Fontan circulation that need to be ruled out are cavoatrial shunting, thrombus formation, and obstruction of the systemic venous pathways. Unobstructed cavopulmonary anastomosis or conduit flow shows a normal biphasic flow pattern of moderate velocity $(0.2-0.5 \mathrm{~m} / \mathrm{s})$. Pulsed-wave Doppler interrogation showing a velocity of greater than $1.5 \mathrm{~m} / \mathrm{s}$ indicates obstruction. Pulsed-wave Doppler in the pulmonary artery should show increase in flow with inspiration during spontaneous ventilation. ${ }^{21}$

Pulmonary reverse flow patterns may be associated with postoperative morbidity such as length of chest tube drainage but did not predict mortality. ${ }^{22}$ Baffle leak evaluation is essential because it is a common cause of desaturation in these patients. Color Doppler flow mapping showing continuous right to left shunting with turbulent flow at the atrial level is characteristic (see Fig. 4C).

Obstructed pulmonary vein flow has been described as a complication of LT Fontan (especially right upper pulmonary vein) and all 4 pulmonary veins should be interrogated before and after the repair. Gradients more than $5 \mathrm{~mm} \mathrm{Hg}$ may require surgical revision by enlarging the communication between the pulmonary veins and the atrium, or adjusting the position of the Fontan baffle. ${ }^{23}$

Patients with single ventricles are at risk of progressive systemic ventricular diastolic and systolic dysfunction. ${ }^{24}$ Standard methods of examining wall motion, calculating ejection fraction, and evaluating function are difficult to apply with the singleventricular morphology of the Fontan conversion candidate. However, ventricular function should always be examined intraoperatively and compared with prior studies. Patients with severely decreased ventricular function have a greater incidence of early death than those with normal function ( $35 \%$ vs $4 \%$, respectively). ${ }^{25}$ 

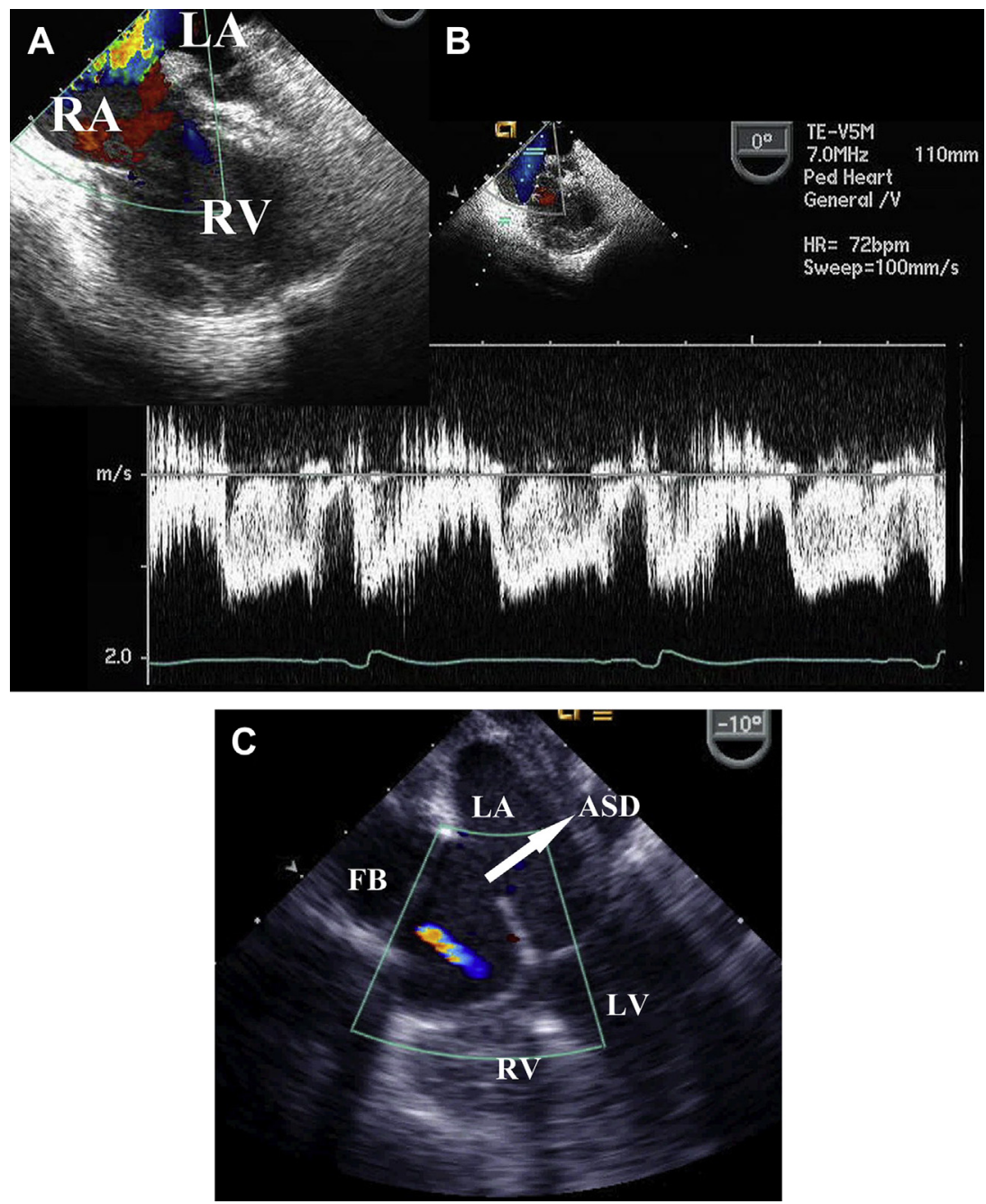

Fig. 4. (A) Doppler color image showing flow acceleration at the atrial septal communication in a patient with Fontan repair for hypoplastic left heart syndrome. Note the absent LV cavity. LA, left atrium. (B) Pulse wave Doppler interrogating the flow acceleration at the atrial septal communication with a velocity of $1.5 \mathrm{~m} / \mathrm{s}$. (C) Midesophageal 4-chamber view of a patient with tricuspid atresia palliated with a Fontan procedure. Note the color flow through the Fontan baffle (FB) to the common atrium and the atretic RV. ASD, atrial septal defect.

\section{Anesthetic Considerations}

\section{Venous capacitance and tone}

Single-ventricle physiology is a peculiar circulation, in which the pulmonary ventricle is absent as an effective pump and thus unable to provide pulsatile blood flow to the pulmonary arteries. Systemic venous return to the lungs is a passive phenomenon and depends on blood volume, peripheral venous capacitance, and the gradient between central venous pressure, pulmonary vascular resistance, and atrial pressure. 
The energy generated by the single ventricle needs to overcome peripheral vascular resistance and contribute to propulsion of venous return from the lower extremities to the pulmonary vascular bed. Venous vascular capacitance and compliance are decreased in Fontan physiology to sustain the increased venous pressure needed to perfuse the pulmonary circulation and provide enough preload to the single ventricle (Fig. 5). This increased resting peripheral venous and vasomotor tone in Fontan patients is associated with a slightly increased plasma norepinephrine level. ${ }^{26}$ This is an adaptive mechanism developed in response to chronic exposure to the Fontan circulation, preventing the onset of edema. Fontan patients have an attenuated cardiac output response to exercise caused by the increased resting venous tone, which limits their ability to mobilize blood from capacitance vessels and contributes to impaired cardiovascular response to exertion. In situations of Fontan circulation failure, venous hypertension develops, causing generalized edema and PLE.

The anesthetic goals are to maintain an adequate preload and to avoid sudden venous pooling with sedation and induction of anesthesia. Fontan patients are volume dependent, so prolonged nil-by-mouth status should be avoided and liberal fluid intake encouraged. Patients should optimally be scheduled as the first case of the day and/or have an intravenous (IV) catheter placed to provide fluid intake during the nil-by-mouth period. Volume load before induction is indicated in most Fontan patients. Selection of induction, hypnotic, and muscle-relaxant agents must consider the impact on venous vasodilatation resulting in sudden hypotension. ${ }^{27}$ Etomidate is commonly used for induction because of its stable cardiovascular profile, whereas agents such as propofol that significantly affect arterial and venous tone should be administered cautiously, if at all.

Once positive-pressure ventilation is initiated after induction of anesthesia, passive venous return diminishes because of positive intrathoracic pressure, causing desaturation and decreased cardiac output. A ventilatory strategy should be used that preserves pulmonary blood flow and optimizes oxygen delivery, which is achieved

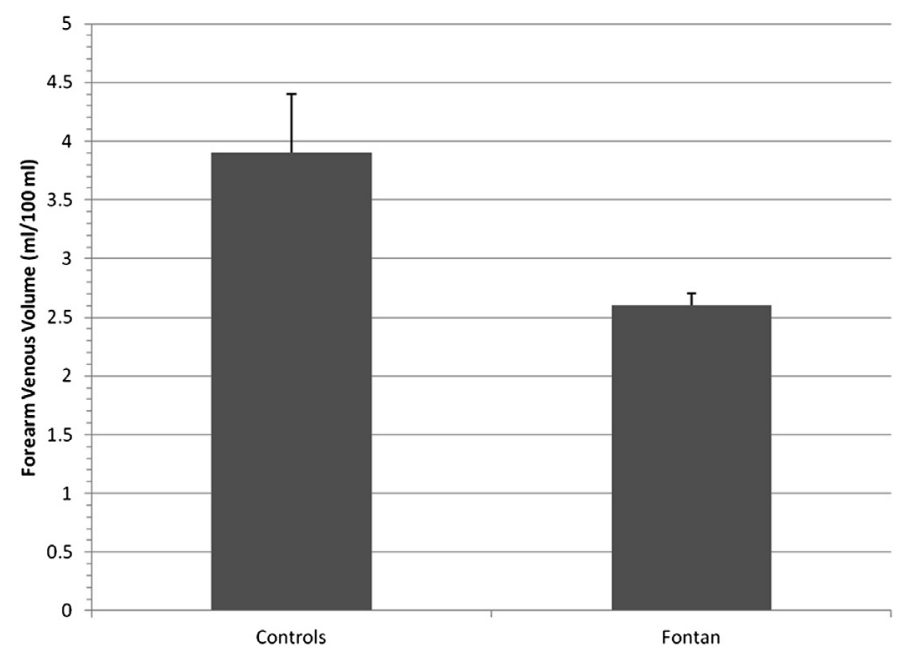

Fig. 5. Increased forearm venous volume during $40 \mathrm{~mm} \mathrm{Hg}$ venous congestion of control and Fontan subjects $(P<.05)$. (Data from Kelley JR, Mack GW, Fahey JT. Diminished vascular capacitance in patients with univentricular hearts after the Fontan operation. Am J Cardiol 1995;76:158-63; with permission.) 
by limiting peak inspiratory pressure $\left(<20 \mathrm{~cm} \mathrm{H} \mathrm{H}_{2} \mathrm{O}\right)$, using low respiratory rates ( $<20$ breaths per minute) and short inspiratory times, avoiding excessive positive end-expiratory pressure, and incorporating higher tidal volumes $(10-15 \mathrm{~mL} / \mathrm{kg})$.

\section{Arrhythmia}

Supraventricular arrhythmias are a common complication in Fontan physiology. Fifty percent of the patients experience atrial tachycardia at 20 -year follow-up. ${ }^{28}$ Atrial contribution to ventricular filling (atrial kick) is important in patients with singleventricle physiology, especially those with impaired diastolic relaxation. The limited contractile and preload reserves increase the dependency on heart rate to increase cardiac output.

The mechanism of the arrhythmia is most commonly macro reentry within atrial muscle caused by extensive suture lines, stretched atrial tissue, and damaged sinoatrial node artery flow. Residual hemodynamic abnormalities such as AVV regurgitation causing chronic atrial hypertension may also contribute to arrhythmia generation. Fontan patients are at increased risk of sudden death caused by either intra-atrial reentrant tachycardia with 1:1 conduction, or ventricular arrhythmias.

Arrhythmias that are hemodynamically compromising should be quickly addressed by cardioversion because circulatory collapse is imminent. Most of these patients are anticoagulated, avoiding the need for TEE before cardioversion. An electrophysiologic evaluation should be considered preoperatively, and radiofrequency ablation of the reentrant pathway in the cardiac electrophysiology laboratory is possible but is a challenging procedure because of the anatomic variations. Medical treatment with antiarrhythmic drugs should be used with the goal of rate control and/or cardioversion. Despite being a common preoperative finding in patients presenting for Fontan conversion, there is no consensus on the optimal medical treatment of arrhythmias, or the timing to refer a patient with a failing Fontan to avoid further progression of arrhythmias. $^{29}$

During Fontan conversion surgery, most patients require a right atrial maze for reentrant atrial tachycardia, and/or a Cox maze III for atrial fibrillation. ${ }^{17}$ Pacemaker insertion is necessary in $50 \%$ of patients.

\section{PLE}

PLE is a condition related to gastrointestinal venous congestion resulting in impaired lymphatic drainage and malabsorption. The reported prevalence of PLE in patients with a failed atriopulmonary Fontan ranges from $2.5 \%$ to $24 \%$ with $50 \%$ mortality within 5 years after diagnosis. ${ }^{30}$ Patients presenting with PLE for Fontan conversion have undergone multiple treatment strategies including diuretics, afterload reduction, supplemental high-protein/low-fat diet, and attempts at halting intestinal protein leak with heparin or steroids, creation of a fenestration, or atrial pacing. Silvilairat and colleagues $^{30}$ described the following as risk factors for mortality in Fontan patients with PLE: symptomatic depressed ventricular function (NYHA class III or IV), low serum albumin level $(<2.5 \mathrm{~g} / \mathrm{dL})$, and/or short atrioventricular flow deceleration time ( $<120$ milliseconds). The effect of protein loss on maturation has been documented in patients whose growth and development is impaired, or with delayed onset of puberty.

The diagnosis of PLE requires the following criteria: hypoproteinemia ( $\leq 6.0 \mathrm{~g} / \mathrm{dL})$, hypoalbuminemia $(\leq 3.0 \mathrm{~g} / \mathrm{dL})$ for more than 3 months, and/or increased fecal alpha1-antitrypsin clearance ( $>27 \mathrm{~mL} / \mathrm{d}$ ) in the absence of liver or renal disease, and accompanying ascites, pleural effusions, edema, diarrhea, or abdominal pain for 3 months or longer. In addition, lymphocytopenia has been observed in PLE but it 
has not been related with recurrent infection or sepsis. The cause of PLE in the failing Fontan is postulated to be related to activation of the renin-angiotensin system, with high mesenteric resistance and low pulmonary vascular compliance. ${ }^{31}$

PLE has been associated with gastrointestinal bleeding. The mechanism is not clear, and several factors have been implicated such as increased venous pressure, infection, or immune-mediated inflammation along with antiplatelet and/or anticoagulant therapy.

PLE leads to severe hypoalbuminemia and consideration must be given to the alteration in action and duration of anesthetic drugs that are highly protein bound. ${ }^{32}$ Albumin is a major carrier for acidic drugs such as etomidate. Hypoalbuminemiareduced binding to etomidate (normally $76 \%$ bound) increases its unbound fraction, thus enhancing its effects.

\section{Coagulation and bleeding risk}

Baseline coagulation defects exist in patients with Fontan physiology. Most Fontan patients have an increased risk of thrombosis caused by increased factor VIII and decreased anticoagulant protein $\mathrm{C}$ and S concentrations. ${ }^{33}$ Factor VIII levels greater than $150 \%$ of normal are observed in patients with a failing Fontan, and are associated with a 5-fold to 6-fold increased risk for venous thrombosis. Thrombotic events occur in up to $33 \%$ of Fontan patients, with increasing risk in those with a failing pathway. It has been suggested that the increase of plasma factor VIII concentrations may be caused by upregulation of factor VIII synthesis by inflamed liver sinusoidal endothelium. PLE may also contribute to the increased incidence of thromboembolism as a consequence of anticoagulant proteins $\mathrm{C}$ and $\mathrm{S}$, and antithrombin III loss. ${ }^{34}$

In contrast, patients with a failed Fontan have bleeding propensity caused by increased systemic venous pressure, liver congestion, the presences of collateral vessels, and the frequent use of antithrombotic therapy. Anticoagulant therapy (aspirin or warfarin) is frequently used in the failing Fontan presenting for Fontan conversion, thus increasing the risk of postoperative coagulopathy and transfusion requirements. The decision for longer-term anticoagulation therapy is influenced by the anticipated risk for thrombosis, often based on the surgical technique, presence of arrhythmias, and a patient's functional status.

The use of antifibrinolytics is controversial in Fontan patients. As mentioned previously, Fontan patients are at risk for thrombosis but hyperfibrinolysis is possible in patients with failing Fontan physiology and liver congestion who undergo surgical revision on bypass. Fontan circulation is prone to endothelial dysfunction indicated by raised levels of von Willebrand factor, and fibrinolysis is preserved. ${ }^{35}$ Antifibrinolytic usage was not associated with early baffle fenestration closure after the modified Fontan procedure and they should be administered judiciously. ${ }^{36}$

\section{Lactic acidosis}

Hyperlactatemia $(\mathrm{HL})$ during cardiopulmonary bypass (CPB) is common in adults following repair of $\mathrm{CHDs}$ and is associated with an increased postoperative morbidity. $\mathrm{HL}$ seems to be related mainly to insufficient oxygen delivery (type A). HL correlates with bypass duration and low oxygen delivery $\left(<260 \mathrm{~mL} / \mathrm{min} / \mathrm{m}^{2}\right)$ and is associated with hyperglycemia. ${ }^{37}$

Late onset $\mathrm{HL}(>3 \mathrm{mmol} / \mathrm{L})$ in the intensive care unit is common ( $>44 \%$ ) following Fontan repair. The incidence in Fontan patients is significantly higher than in a group of mixed congenital surgeries despite similar CPB times, and may be related to increased catecholamine use. Late-onset HL has not been associated with adverse 


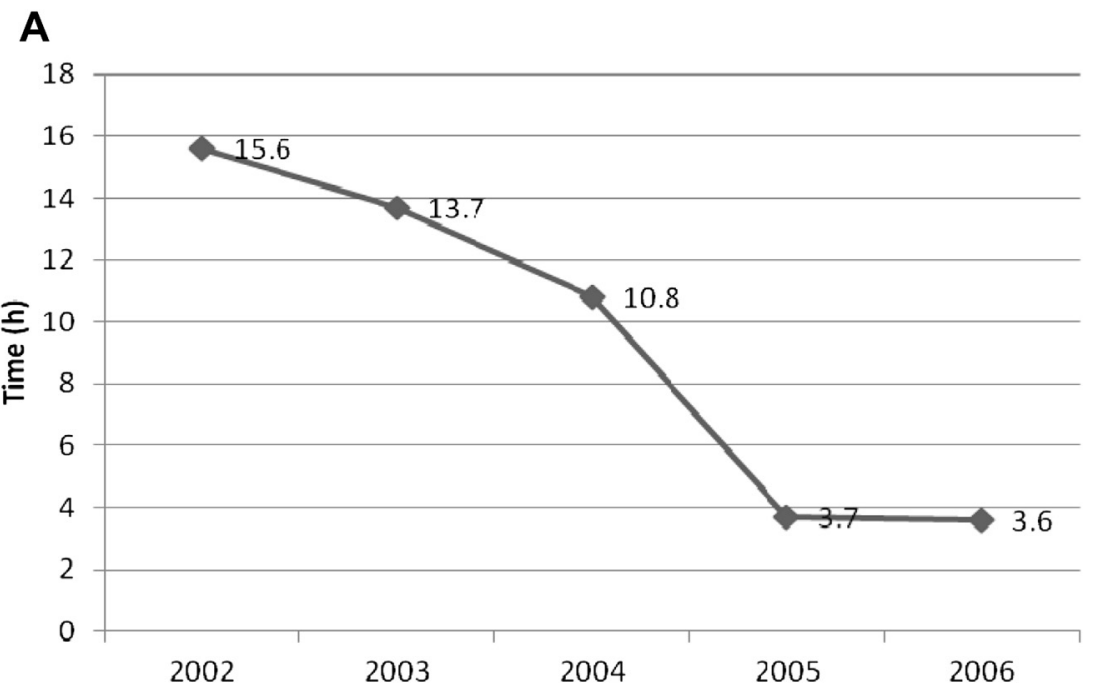

B

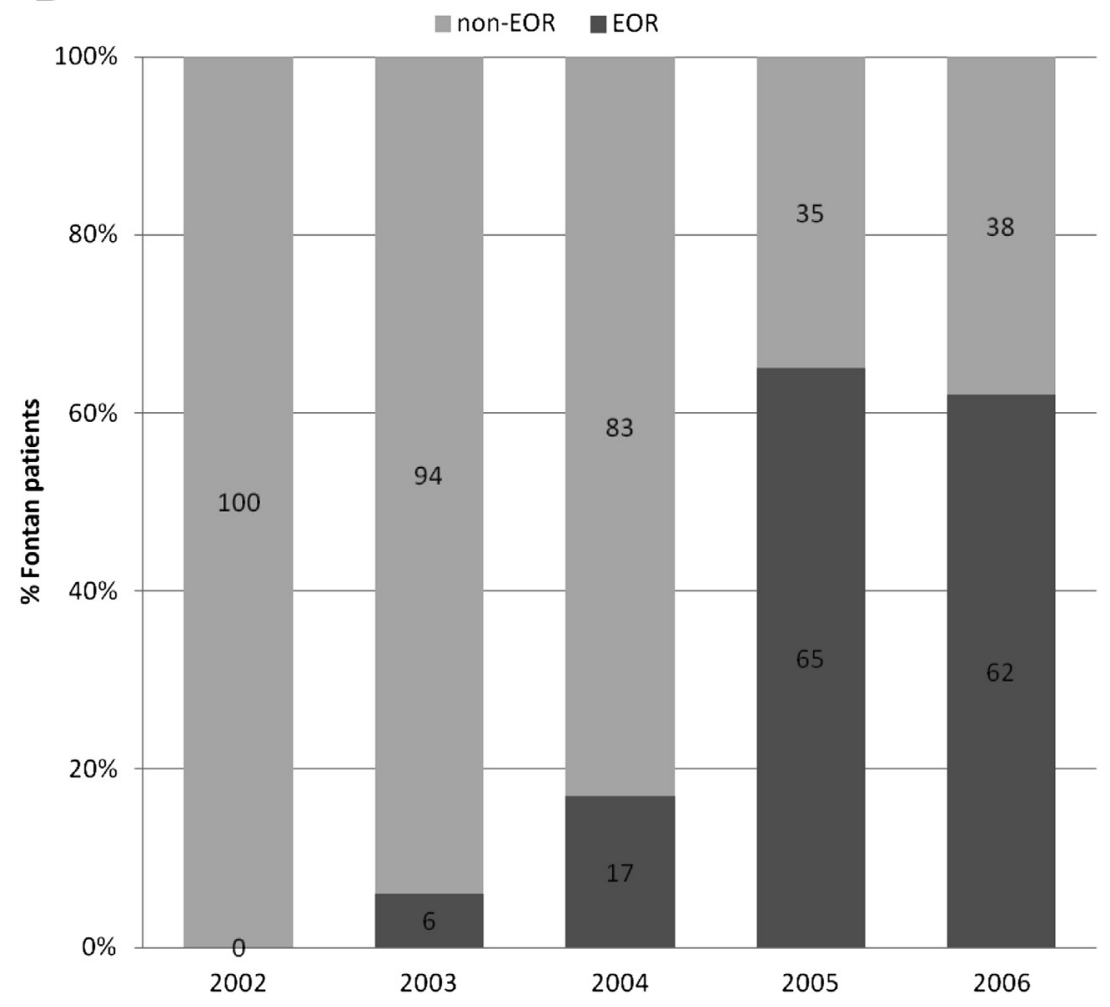

Fig. 6. (A) Mean time to extubation following Fontan repair. (B) Proportion of Fontan patients extubated in the operating room (EOR). (Data from Morales DL, Carberry KE, Heinle JS et al. Extubation in the operating room after Fontan's procedure: effect on practice and outcomes. Ann Thorac Surg 2008;86:576-82; with permission.) 
outcomes, and thus should be interpreted carefully. ${ }^{38}$ Hyperglycemia should be corrected and, if possible, catecholamine use limited.

\section{Early extubation}

There are several clinical benefits for early extubation following Fontan repair or conversion. First, it decreases the complications from mechanical ventilation and intubation such as laryngotracheal trauma, nosocomial pneumonia, and hypertensive crises caused by airway manipulation. In addition, Fontan physiology benefits from negative inspiratory pressure to improve pulmonary blood flow. Early extubation also decreases intensive care unit and hospital stay, decreasing the cost per admission. ${ }^{39}$

However, there are considerations for remaining intubated in the immediate postoperative period, such as avoiding hemodynamic instability or the risk of atelectasis and lung collapse causing hypoxia. Criteria for early extubation include an otherwise healthy patent with few comorbidities and an uneventful surgery with short CPB and aortic cross-clamp times (<90 minutes). Ongoing coagulopathy precludes early extubation because of the potential need for surgical reexploration. The anesthetic should be tailored to allow extubation in the operating room by limiting the total amount of narcotics, sedatives, and muscle relaxants.

At Texas Children's Hospital we embarked on a program to achieve safe early extubation in the operating room for patients undergoing Fontan repair and revision starting in 2002 (Fig. 6). The average time to extubation decreased (15.6 hours in 2002 to 3.6 hours in 2006), and the proportion of Fontan patients extubated in the operating room increased from $0 \%$ to $62 \% .{ }^{40}$ Our current practice relies on inhalation anesthetics, short-acting narcotics, judicious use of muscle relaxants, and the use of dexmedetomidine for postoperative sedation. However, although the Fontan conversion patient presents with more comorbidities, a higher risk of postoperative bleeding, and the need for a more cautious approach to early extubation, with adherence to a similar team approach for the postoperative care of these patients, the average mechanical ventilation duration has decreased to 3.6 hours in children undergoing a primary Fontan, and $1.5 \pm 0.3$ days in our series of adults undergoing redo Fontan conversion surgery."

\section{SUMMARY}

The growing population of adults with CHD requires surgical and catheter interventions and revisions of their initial repairs. These patients require the expertise of a team of surgeons, cardiologists, anesthesiologists, and intensive care physicians who are familiar with their lesions, the options and evolution of repairs, and the consequences of their disease. This requirement is clearly shown in the adult with single ventricular physiology with a failed primary Fontan repair presenting for a Fontan conversion surgery.

\section{REFERENCES}

1. Mascio C, Pasquali S, Jacobs J, et al. Outcomes in adult congenital heart surgery: analysis of the Society of Thoracic Surgeons database. J Thorac Cardiovasc Surg 2011;142:1090-7.

2. Marelli AJ, Mackie AS, lonescu-Ittu R, et al. Congenital heart disease in the general population: changing prevalence and age distribution. Circulation 2007;115:163-72. 
3. Society of Thoracic Surgeons, STS Congenital Heart Surgery Database Executive Summary - Adults, [Online]. Available at: http://www.sts.org/sites/default/files/ documents/STSExecSummary_Adults.pdf. Accessed October 29, 2012.

4. Dearani J, Mavroudis C, Quintessenza J, et al. Surgical advances in the treatment of adults with congenital heart disease. Curr Opin Pediatr 2009;21:565-72.

5. Giamberti A, Chessa M, Abella R, et al. Morbidity and mortality risk factors in adults with congenital heart disease undergoing cardiac reoperations. Ann Thorac Surg 2009;88:1284-90.

6. Karamlou T, Diggs B, Ungerleider R, et al. Adults or big kids: what is the ideal clinical environment for management of grown-up patients with congenital heart disease? Ann Thorac Surg 2010;90:573-9.

7. Fontan F, Baudet E. Surgical repair of tricuspid atresia. Thorax 1971;4:240-8.

8. Kreutzer G, Galindez E, Bono H, et al. An operation for the correction of tricuspid atresia. J Thorac Cardiovasc Surg 1973;66:613-21.

9. Angeli E, Napoleone C, Balducci A, et al. Natural and modified history of singleventricle physiology in adult patients. Eur J Cardiothorac Surg 2012;42(6): 996-1002.

10. Petko M, Myung R, Wernovsky G, et al. Surgical reinterventions following the Fontan procedure. Eur J Cardiothorac Surg 2003;24:255-9.

11. Fontan F, Kirklin JW, Fernandez G, et al. Outcome after a "perfect" Fontan operation. Circulation 1990;81:1520-36.

12. Khairy P, Fernandes SM, Mayer JE, et al. Long term survival, modes of death, and predictors of mortality in patients with Fontan surgery. Circulation 2008;117:85-92.

13. Lardo AC, del Nido PJ, Webber SA, et al. Hemodynamic effect of progressive right atrial dilatation in atriopulmonary connections. J Thorac Cardiovasc Surg 1997;114:2-8.

14. D'Udekem Y, Cheung MM, Setyapranata S, et al. How good is a good Fontan? Quality of life and exercise capacity of Fontans without arrhythmias. Ann Thorac Surg 2009;88:1961-89.

15. Morales DL, Dibardino DJ, Braud BE, et al. Salvaging the failing Fontan: Iateral tunnel versus extracardiac conduit. Ann Thorac Surg 2005;80:1445-52.

16. Backer CL, Deal BJ, Kaushal S, et al. Extracardiac versus intra-atrial lateral tunnel Fontan: extracardiac is better. Semin Thorac Cardiovasc Surg Pediatr Card Surg Annu 2011;14:4-10.

17. Mavroudis C, Backer CL, Deal BJ. Late reoperations for Fontan patients: state of the art invited review. Eur J Cardiothorac Surg 2008;34:1034-40.

18. Takahashi K, Fynn-Thompson F, Cecchin F, et al. Clinical outcomes of Fontan conversion surgery with and without associated arrhythmia intervention. Int J Cardiol 2009;137:260-6.

19. Koh $M$, Yagihara $T$, Uemura $H$, et al. Optimal timing of the Fontan conversion: change in the P-wave characteristics precedes the onset of atrial tachyarrhythmias in patients with atriopulmonary connection. J Thorac Cardiovasc Surg 2007;133:1295-302.

20. Gologorsky E, Gologorsky A, Rosenkranz E. An adult patient with Fontan physiology: a TEE perspective. Anesthesiol Res Pract 2012;475015:1-5.

21. Russell IA, Rouine-Rapp K, Stratmann G, et al. Congenital heart disease in the adult: a review with internet-accessible transesophageal echocardiographic images. Anesth Analg 2006;102:694-723.

22. Leyvi G, Bennett HL, Wasnick JD. Pulmonary artery flow patterns after the Fontan procedure are predictive of postoperative complications. J Cardiothorac Vasc Anesth 2009;23:54-61. 
23. Padalino MA, Saiki $Y$, Tworetzky W, et al. Pulmonary venous pathway obstruction from recurrent restriction at atrial septum late after Fontan procedure. J Thorac Cardiovasc Surg 2004;127:281-3.

24. Moniotte SLJ, Barrea C. Functionally univentricular heart. In: Lai WW, Mertens LL, Cohen MS, et al, editors. Echocardiography in pediatric congenital heart disease. 1st edition. West Sussex (United Kingdom): Wiley-Blackwell; 2009. p. 459-75.

25. Piran S, Veldtman G, Siu S, et al. Heart failure and ventricular dysfunction in patients with single or systemic right ventricles. Circulation 2002;105:1189-94.

26. Kelley JR, Mack GW, Fahey JT. Diminished vascular capacitance in patients with univentricular hearts after the Fontan operation. Am J Cardiol 1995;76:158-63.

27. Krishnan US, Taneja I, Gewitz M, et al. Peripheral vascular adaptation and orthostatic tolerance in Fontan physiology. Circulation 2009;120:1775-83.

28. Weipert J, Noebauer C, Schreiber C, et al. Occurrence and management of atrial arrhythmia after long-term Fontan circulation. J Thorac Cardiovasc Surg 2004; 127:457-64.

29. Anderson PA, Breitbart RE, McCrindle BW, et al. The Fontan patient: inconsistencies in medication therapy across seven Pediatric Heart Network centers. Pediatr Cardiol 2010;31:1219-28.

30. Silvilairat S, Cabalka AK, Cetta F, et al. Protein-losing enteropathy after the Fontan operation: associations and predictors of clinical outcome. Congenit Heart Dis 2008;3:262-8.

31. Yu JJ, Yun TJ, Yun SC, et al. Low pulmonary vascular compliance predisposes post-Fontan patients to protein-losing enteropathy. Int J Cardiol 2011. [Epub ahead of print].

32. Trojnarska O, Ciepłucha A. Challenges of management and therapy in patients with a functionally single ventricle after Fontan operation. Cardiol J 2011;18: 119-27.

33. Odegard KC, McGowan FX Jr, Zurakowski D, et al. Procoagulant and anticoagulant factor abnormalities following the Fontan procedure: increased factor VIII may predispose to thrombosis. J Thorac Cardiovasc Surg 2003;125:1260-7.

34. Odegard KC, Zurakowski D, DiNardo JA, et al. Prospective longitudinal study of coagulation profiles in children with hypoplastic left heart syndrome from stage I through Fontan completion. J Thorac Cardiovasc Surg 2009;137:934-41.

35. Binotto MA, Maed NY, Lopes AA. Altered endothelial function following the Fontan procedure. Cardiol Young 2008;18:70-4.

36. Gruber EM, Shukla AC, Reid RW, et al. Synthetic antifibrinolytics are not associated with an increased incidence of baffle fenestration closure after the modified Fontan procedure. J Cardiothorac Vasc Anesth 2000;14:257-9.

37. Ranucci M, De Toffol B, Isgrò G, et al. Hyperlactatemia during cardiopulmonary bypass: determinants and impact on postoperative outcome. Crit Care 2006;10: 1-9.

38. Hamamoto $\mathrm{M}$, Imanaka $\mathrm{H}$, Kagisaki $\mathrm{K}$, et al. Is an increase in lactate concentration associated with cardiac dysfunction after the Fontan procedure? Ann Thorac Cardiovasc Surg 2005;11:301-6.

39. Mutsuga M, Quiñonez LG, Mackie AS, et al. Fast-track extubation after modified Fontan procedure. J Thorac Cardiovasc Surg 2012;144:547-55.

40. Morales DL, Carberry KE, Heinle JS, et al. Extubation in the operating room after Fontan's procedure: effect on practice and outcomes. Ann Thorac Surg 2008;86: 576-82. 